\title{
OLAYO DÍAZ GIMÉNEZ (1810-1885): UN BUEN EJEMPLO DE CIENTÍFICO «INTERMEDIO»
}

\author{
Carlos López Fernández \\ Dr. en Ciencias Físicas. Catedrático de Matemáticas \\ del I.B. Alfonso X el Sabio (Murcia)
}

\section{Manuel Valera Candel}

Dr. en Ciencias Físicas. Profesor Titular de Historia de la Ciencia. Dpto. de Ciencias Socio-sanitarias. Facultad de Medicina. Campos de Espinardo. Universidad de Murcia

\section{RESUMEN}

En este trabajo se ofrece una panorámica general sobre la vida y obra del catedrático Olayo Díaz Giménez (1810-1885), referida sobre todo a la etapa que vivió en la ciudad de Murcia, a la que llegó en 1862 y donde ya permaneció hasta su muerte.

El trabajo ha sido estructurado en cuatro apartados, dentro de los cuales, junto a una reseña biográfica, se aborda la labor de Díaz como docente, como propagador de la ciencia de su época y como encargado de la Estación meteorológica. A su vez, dentro de la primera de estas facetas, destacó como forjador del Gabinete de Física del Instituto Provincial; dentro de la segunda, por sus colaboraciones en la prensa y como introductor en Murcia de las teorías evolucionistas; y dentro de la tercera, como autor de numerosas observaciones y de un libro sobre la meteorología murciana.

De acuerdo con nuestro estudio, Olayo Díaz, además de mostrarse como uno de los científicos clave de la Murcia decimonónica, aparece como típico representante de los llamados «científicos intermedios», o aquéllos que sin poseer una obra propia destacada, colaboraron decisivamente a crear y mantener las condiciones necesarias para que la actividad científica arraigara en España.

\section{SUMMARY}

In this paper we offer a general view of the life and work of Olayo Diaz Giménez (1810-1885), especially during his stage in the city of Murcia, where he lived from 1862 to his death.

The paper is divided into four sections. After providing a biographical account of Olayo Díaz, his work as a teacher is approached, with emphasis on his role in the creation of the Physics Cabinet at the Provincial Institute (Secondary School). The following section highlights his activity in promoting the science of his time through his collaborations in the local newspapers and his involvement in the introduction of evolutionism in Murcia. Finally, we look at his period in charge of the Meteorological Office, with emphasis on both his observations as his book on the weather of Murcia.

As a result of our study, Olayo Diaz appears as one of the key-scientists in the Murcia of the $\mathrm{XIX}^{\text {th }}$ century, and as a typical representative of so-called «intermediate scientists», or those that, without possessing an outstanding work of their own, collaborated decisively to create and maintain the necessary conditions to promote scientific activity in Spain. 


\section{VIDA, ENTORNO VITAL Y SIGNIFICACIÓN CIENTÍFICA}

Una breve cita, alusiva a las relaciones religión-ciencia y debida al personaje que motiva el presente trabajo, nos servirá de introducción:

\footnotetext{
«La fé es una luz que ha de percibirse con los ojos cerrados; la razón es otra luz, que sólo se percibe con los ojos abiertos. Hay dos maneras de ilustrarse: creyendo o racionizando; el primer procedimiento es más seguro y sencillo porque no exige estudio ni pruebas. La fé es una creencia sentida, la ciencia debe ser una creencia demostrada. La fé exalta la imaginación; la verdadera ciencia ilustra y fortifica el juicio. Donde comienza la fé acaba la ciencia, y... cada uno puede ser dichoso a su manera» 1
}

El autor de estas certeras palabras no fue ningún científico célebre, sino un modesto profesor de Física del Instituto Provincial de Murcia que ejerció durante el siglo XIX. Su nombre era Olayo Díaz Giménez y fue un típico hijo de su tiempo. Hombre de vasta formación humanística y científica, de convicciones progresistas y notable capacidad de trabajo, tras fijar su residencia en la capital murciana en 1862, no tardó en convertirse en uno de los máximos protagonistas de los ambientes científicos de la misma.

Las lógicas limitaciones que encontró durante su estancia en esta sencilla ciudad de provincias, como ya le había ocurrido en otros destinos previos, le impidió llevar a cabo una producción científica propia de entidad; aunque ciertas aportaciones sí que merezcan cuando menos citarse (sobre todo, en Meteorología). No deja de ser sintomático en este terreno que, cuando el sugestivo médico y librepensador murciano José Hernández Ardieta (asiduo de la tertulia científica de E. Littré en París) fue presentado en 1867 al secretario perpetuo del Instituto de Francia, éste le preguntase por «el eminente astrónomo murciano don Olayo Díaz, cuyas comunicaciones eran recibidas y publicadas por el Instituto» ${ }^{2}$.

Pero donde sin duda Olayo desempeñó un sobresaliente papel fue como difusor de la ciencia, tanto desde su cátedra como a través de algunas publicaciones propias y medios de comunicación de la época. Participó, además, de forma activa en la creación de algunas instituciones científicas (Universidad Libre, Agrupación cultural liceística, etc...) de notable interés en la Murcia decimonónica; y, como después veremos, dotó de una sólida infraestructura material y bibliográfica al Instituto.

Aunque su labor creativa no fuese muy relevante, ayudó decisivamente a crear y mantener el caldo de cultivo necesario para que, a la larga, otros pudieran afrontarla

1 DíAZ GimÉNEZ, O. (1879), «Discurso inaugural del Liceo de Murcia», Semanario Murciano, 56.

2 GARCía ABELLÁN, J.(1979), Hernández-Ardieta, el librepensador murciano, Murcia, Academia Alfonso X, p.44. Hemos recogido textualmente la cita, pero entendemos que el Secretario del Instituto de Francia querría aludir a aportaciones de Olayo Díaz referentes a observaciones meteorológicas, pues no nos consta que éste tuviese dedicación especial a cuestiones de tipo astronómico. 
en condiciones adecuadas. Se nos manifiesta así Olayo Díaz como un típico representante de lo que López Piñero llama «científico intermedio» ${ }^{3}$. Pero en este caso, tenemos el interés añadido de referirnos a un personaje geográficamente alejado de los focos de producción científica del país; residente en una ciudad como Murcia, dominada por una de esas burguesías débiles e inmovilistas que tanto lastraron nuestro desarrollo científico-tecnológico.

Algunas aproximaciones a la labor de Díaz, han sido ya concretadas a través de varios trabajos histórico-científicos relativos a la Región Murciana. Estos han estado centrados en aspectos como la ciencia en el Instituto de Segunda Enseñanza ${ }^{4}$, la difusión general del conocimiento científico en los medios de comunicación regionales ${ }^{5}$, o en el desarrollo en dicho ámbito de las teorías evolucionistas ${ }^{6}$. Pero faltaba sin duda un estudio monográfico sobre la labor científica de Olayo Díaz en tierras murcianas, tema en el que ya se dio un primer paso, aunque centrado en su labor como docente $^{7}$. En el presente trabajo, abordamos ya el tema de forma general, integrando y ampliando todas las informaciones previas sobre la labor de Díaz, y procurando interpretar el auténtico significado de éste dentro de su particular contexto vital.

Pero antes de adentrarnos en su labor científica, una breve reseña biográfica se hace imprescindible ${ }^{8}$. Nacido en Almadén (Ciudad Real, 1810), Olayo Díaz Giménez cursó sus estudios medios como interno en el Real Colegio de la Asunción de Córdoba (1827-30), donde nada más terminar, dado su excelente aprovechamiento, llegó a ejercer como regente de las cátedras de Latinidad, Física y Etica (1830-32). Inició su formación científica en 1832, al matricularse en el Museo de Ciencias Naturales de

3 Ver, por ejemplo: LóPEZ PiÑERO, J.M. (1982), La ciencia en la historia hispánica, Barcelona, Salvat, pp. 56-57, o bien, GonZÁlez Blasco, P.; JimÉnEZ BlANCO; LóPEZ PiÑERO J.M. (1979), Historia y sociología de la ciencia en España, Madrid, Alianza Editorial, pp. 76-82

4 López FernÁndeZ, C.; VAlERA, M.; MARSET, P. (1988): «La Ciencia en un Instituto de Segunda Enseñanza durante el período (1860-1916)», in M. Esteban et al. (ed.) Estudios sobre Historia de la Ciencia y de las Técnica, 1, Valladolid, Junta de Castilla-León, 505-518, o también, LóPEZ FERNÁNDEZ, C.; VIDAL DE LABRA, J.A. (1987), «Cincuenta años de ciencia en el Instituto (1860-1916) in Jiménez Madrid, R. (coord.): El Instituto Alfonso X el Sabio: 150 años de historia, Murcia, Editora Regional.

5 LÓPEZ FERnÁNDEZ, C.; VAlERA, M.; MARSET, P. (1991): «Los contenidos científicos del Semanario Murciano (1878-1881)», in M. VALERA y C. LÓPEZ FERNÁNDEZ (eds.) Actas del V Congreso de la Sociedad Española de Historia de las Ciencias y de las Técnicas, 1, Murcia, PPU, 401-420, y también, LÓPEZ FERnÁNDEZ, C., MARSET, P. (1997), «La agricultura científica en la prensa murciana del s. XIX a través de los autores autóctonos», Dynamis, 17, pp. 239-258

6 LÓPEZ FERnÁnDEZ, C.; VALERA, M.; LóPEZ SÁNCHEZ, J.F. (1994): «El evolucionismo en Murcia (1870-1880) a través de la prensa cultural y científica», Llull, 17, pp. 89-102.

7 López Fernández, C.; VALERA, M. (1.998): «La labor del catedrático Olayo Díaz Jiménez (1810-1885) en el Instituto Provincial de Segunda Enseñanza de Murcia» en J.L. García Hourcade et al (coord.) Estudios de Historia de las Técnicas, la Arqueología Industrial y las Ciencias, Salamanca, Junta de Castilla y León, vol. II, pp. 849-857.

8 La mayor parte de los datos biográficos de Olayo Díaz, han sido obtenidos a partir del expediente personal del mismo conservado en el actual Instituto Alfonso X el Sabio. 
Madrid de las asignaturas de Botánica y Agricultura, y en el antiguo Conservatorio de Artes de Física Experimental.

En 1833 ingresó en el Colegio Nacional de Medicina y Cirugía de San Carlos, donde obtuvo el grado de licenciado en 1840. De su hacer como médico destaca el logro de la Cruz de Epidemias, por la labor desarrollada en la localidad segoviana de Villaverde de Iscar durante la epidemia colérica de 1854. Pero la principal dedicación profesional de Olayo fue sin duda la docencia. Inició su andadura al ser nombrado en 1842 catedrático interino de Geografía-Historia en el Instituto de Lérida. Allí ocupó los cargos de Secretario y Vicedirector, y «a instancias del jefe político provincial», se responsabilizó del traslado a dicho centro de libros y material científico de la suprimida Universidad de Cervera.

Obtuvo por oposición en 1843 plaza de Ayudante-profesor en el Colegio de Medicina y Cirugía de San Carlos (Madrid), pero pronto volvió a la enseñanza secundaria, al ser nombrado en 1844 catedrático interino de Geografía e Historia y Física y Química en el Instituto de Cuenca. Se mantuvo en dicho centro hasta 1846, cuando «por desavenencias con el jefe político de la provincia» fue separado del servicio. Ganó por fin oposiciones a catedrático titular de Física y Química en 1846, siendo destinado al Instituto Provincial de Pontevedra al año siguiente. En 1851 obtuvo premio de mérito dentro del escalafón de catedráticos.

En el centro gallego ocupó el cargo de Director. Junto a su asignatura de Física y Química, impartió también Historia Política (1847-48) e Historia Natural (1848-49); a consecuencia de esto último, hubo de ocupar plaza de Vocal en la Junta de Agricultura de la provincia. En 1849 recibió el grado de Regente de Historia Natural en la Universidad de Santiago. A petición propia, fue trasladado con posterioridad a los Institutos de Segovia (1850) y Murcia (1862). Este último cambio, motivado por penosas circunstancias familiares, le fue sugerido por el propio director del Instituto murciano y amigo personal suyo, Angel Guirao Navarro (eminente político y naturalista, que llegó a ostentar la presidencia de la Real Sociedad Española de Historia Natural).

Olayo Díaz fue corresponsal de la Academia de Ciencias y socio numerario de: las Sociedades Económicas de Amigos del País de Lérida, Cuenca y Murcia. También desempeñó un destacado papel en la Universidad Libre de Murcia (1869-1874), donde fue nombrado decano de la Facultad de Ciencias e impartió, en los niveles de bachillerato y licenciatura, la disciplina llamada Ampliación de Física Experimental. Curiosamente, fue en esta misma Universidad donde obtuvo en 1872 la licenciatura en ciencias físico-químicas. Meses antes, dictó allí la lección inaugural sobre el tema «Origen y progreso de la Filotecnia».

En el ámbito ideológico, Díaz fue un republicano y federalista convencido, aunque no hay constancia de que desempeñase un papel especialmente activo en los ambientes políticos locales. Su actividad se desarrolló siempre en el terreno menos comprometido de lo social, donde sí alcanzó un notable protagonismo. Así, junto a 
sus frecuentes colaboraciones en la prensa y dilatado ejercicio como profesor de varias generaciones de murcianos, presidió durante algunos años la sección de ciencias de la agrupación cultural progresista «El Liceo», intento de alternativa a una Sociedad Económica de Amigos del País ya alicaída por esos años.

Cuando acaece su fallecimiento, a primeros de Abril de 1885, se hace eco del mismo El Diario de Murcia ${ }^{9}$, que publica una necrológica donde se alude de forma respetuosa (aunque en tono condescendiente) a las ideas políticas de Díaz. Allí se hace énfasis en el hecho de que murió reconciliado con la Iglesia, y se da noticia de que durante el acto civil realizado tras el funeral intervino, como único orador, el famoso dirigente cantonal Antonete Gálvez. A modo de homenaje póstumo, el citado diario editó un suplemento especial, reproduciendo un discurso inédito de Olayo con motivo de la conmemoración en el Casino del centenario de Saavedra Fajardo. El óbito fue comunicado al Rector de la Universidad de Valencia, Director del Observatorio de Madrid y Director General de la Función Pública.

\section{LA LABOR COMO DOCENTE Y COMO DIVULGADOR CIENTÍFICO. INTRODUCCIÓN DE LAS TEORÍAS EVOLUCIONISTAS.}

A partir de su nombramiento como catedrático titular del Instituto de Murcia, Olayo Díaz ejerció en el mismo durante 23 cursos académicos. Al contrario de lo que había hecho en otros centros, en éste sólo impartió la disciplina de Física y Química, sin más variaciones al respecto que las derivadas de los diferentes planes de estudio. Según hemos reflejado en anteriores trabajos, destacó especialmente como responsable del Gabinete de Física ${ }^{10}$, aspecto en el que ya había brillado años antes en Segovia $^{11}$.

Adquirió para el mismo excelentes aparatos, muchos de ellos traídos del extranjero. Se surtió principalmente de casas alemanas (Max Kohl y Zeiss), francesas (Secretan, Gaiffé, Demichel y Fills d'Emmile Deryrolle) y españolas (Viuda de Aramburo); recurrió como intermediario al óptico francés, afincado en Murcia, Michel Dubon. Aunque en este terreno de las adquisiciones Díaz no partió de cero (un año antes de su llegada había ya casi 100 aparatos), su papel fue crucial, pues durante su ejecuto-

9 Ver Diario de Murcia, ejemplar correspondiente al día 8-IV-1885, que puede ser consultado en la Hemeroteca del Archivo Municipal de Murcia.

10 Ver LÓPEZ FERNÁNDEZ, C.; VIDAL DE LABRA, J.A. (1987), obra ya citada en la nota 7, y también A. SÁNCHEZ GonZÁlez (1987), «Museo de Física» in R. Jiménez Madrid (coord.) El Instituto Alfonso X el Sabio: 150 años de historia, Murcia, Editora Regional, pp. 291-311.

11 García Hourcade, J.L.; Rubio, J.L.; VALLÉS, J.M. (1988): «El Gabinete de Física en el Instituto de Segovia en el s.XIX» in M. Esteban (ed) Estudios sobre Historia de la Ciencia y de la Técnica, Valladolid, Junta de Castilla-León, 1, pp. 519-527. 
ria logró quintuplicar la dotación existente, apareciendo catalogados en la memoria del curso 1883-84 más de quinientos aparatos, clasificados en 16 secciones distintas.

Desde el punto de vista docente, el auge del Gabinete de Física fue sin duda algo muy positivo, pues como es sabido, durante el siglo XIX la enseñanza de las disciplinas físico-químicas estaba sobre todo centrada en la comprobación en el aula de determinadas leyes y fenómenos físicos. Los propios libros de texto, una vez enunciadas dichas leyes, volcaban su atención en la descripción de los aparatos de laboratorio con los que poder verificarlas. Y dentro del instrumental traído por Díaz, dejando aparte el de tipo meteorológico (cuya importancia glosaremos después), destaca ante todo su excepcional dimensión didáctica.

El Gabinete de Física tuvo siempre un significado muy especial dentro del Instituto, pues complementaba el espectacular Museo de Historia Natural creado por el Director Guirao, que reunía importantes colecciones geológicas y zoológicas (con más de 3.000 animales disecados). Es sintomático que cuando Alfonso XII visitó el Instituto en 1877, Olayo Díaz realizase ante él varias experiencias relativas al análisis y síntesis del agua.

Pero hombre de gran inquietud intelectual, nunca limitó su labor al terreno docente; participó de lleno en los ambientes culturales de Murcia y desplegó una notable labor como divulgador científico, sobre todo desde la prensa de tipo cultural. La revista El Semanario Murciano (1878-81), órgano de expresión de la institución cultural «El Liceo», fue sin duda el medio donde más se prodigó.

Aparecen allí algunos trabajos suyos sobre temas que impactaron a la Murcia decimonónica, como el editado en Febrero de 1878 con los resultados del análisis físico-químico del aerolito caído cerca de Molina veinte años antes ${ }^{12}$. Hay otro artículo (bastante retórico) dedicado a ensalzar el progreso de la ciencia titulado «El sueño de Pitágoras» ${ }^{13}$. Pero los hubo también de mayor entidad científica, como la serie de siete artículos agrupada bajo el título de «Los errores clásicos» (Enero-Junio de 1880); en ella, Díaz realiza una lúcida reflexión crítica sobre aquellas doctrinas científicoepistemológicas erróneas que, a su juicio, más costaron de superar históricamente: astrología, physiolatría, geocentrismo y antropocentrismo ${ }^{14}$. También puede verse otro trabajo donde quedan recogidas sus opiniones sobre el tema de la emigración ${ }^{15}$.

Como presidente de la sección de ciencias de «El Liceo», su principal aportación fue, sin duda, el discurso que pronunció en el acto inaugural de la misma; pieza oratoria ésta típicamente decimonónica, que supone un auténtico alarde de conocimiento

12 DíAZ GiménEZ, O. (1878) «Aerolito caído el día 24 de diciembre de 1858 en los campos de Molina», El Semanario Murciano, 4.

13 Díaz GiméneZ, O. (1881), «El sueño de Pitágoras», El Semanario Murciano, 174.

14 Díaz GimÉNEZ, O. (1880), «Errores clásicos», El Semanario Murciano, 101, 102, 117, 118, 119, 120 , y 121 .

15 DíAZ GiMÉNEZ (1881), «Informe sobre la emigración», El Semanario Murciano, 192 y 193. 
en casi todas las ramas del saber. Dicho discurso trascendió al público al ser reproducido a lo largo de 43 números de El Semanario Murciano (entre septiembre de 1878 y julio de 1881$)^{16}$. A través de la parte científica del mismo (que abarca unos 29 números), su autor se erige como uno de los principales introductores en Murcia de las teorías evolucionistas, tanto biológicas como geológicas.

Según en otro lugar hemos puesto de manifiesto ${ }^{17}$, las teorías evolucionistas entraron en Murcia a través de la prensa de tipo cultural (no diaria): bajo la tónica de controversia. Dos fueron los científicos protagonistas de la misma: Olayo Díaz desde el bando transformista y Andrés Martínez Cañada desde el creacionista. El primero expuso sus ideas, como ya hemos dicho, en El Semanario Murciano (1878-81), el segundo había hecho lo propio apenas dos años antes desde la revista El Album (1876).

Por lo que respecta al ámbito geológico, Díaz rechaza de plano las ideas catastrofistas de Cuvier, a las que inicialmente contrapone las evolucionistas de Lamarck: y no, como cabía esperar, las actualistas de Lyel. Con todo, finalmente se decanta por las concepciones intermedias de Elie de Beaumont ${ }^{18}$. Aunque esta tónica conciliatoria, se rompe cuando entramos en el ámbito del evolucionismo biológico.

Aquí, las ideas de Olayo Díaz son radicales, al entender que éste ha de ser llevado hasta sus últimas consecuencias. Así, muy en línea con lo que fue el desarrollo del darwinismo en el resto de España ${ }^{19}$, aun antes de abordar las ideas de Darwin ya alude Díaz a las de Haeckel, y en uno de los temas más comprometidos: la síntesis de compuestos orgánicos a partir de la materia inerte. Afirma haber detectado él mismo (aunque accidentalmente) «grumos radiolares de materia albuminoide» junto al cadáver flotante de un batracio que usaba para experimentar. Luego, parafraseando al alemán, dirá:

«(..) por efecto de la virtud o actividad de estos compuestos albuminóides, las formas complejas y los fenómenos vitales de los organismos superiores alcanzan su completa realización. Es un gran triunfo (..) para la biología moderna (..), haber reducido a esos elementos materiales el milagro de los fenómenos vitales, y haber demostrado que las propiedades físicas y químicas (..) de los corpúsculos albuminóides, son las causas esenciales de los fenómenos orgánico-vitales» ${ }^{20}$.

16 DíAZ GimÉNEZ, O. (1879-1881), «Discurso inaugural del Liceo de Murcia», El Semanario Murciano, 33, 34, 35, 36, 37, 39, 40, 41, 43, 46, 48, 50, 52, 54, 56, 58, 61, 64, 69, 72, 75, 79, 85, 89, 91, 94, $95,104,107,112,114,125,126,129,131,138,142,145,154,156,159,168$ y 176.

17 científica», Llull, 17 ( $\left.n^{\circ} 32\right)$, pp. 89-102.

17 LÓPEZ FERNÁNDEZ et. al. (1994), «El evolucionismo en Murcia (1870-1880) a través de la prensa cultural y científica», Llull, 17 ( $\left.n^{\circ} 32\right)$, pp. 89-102.

18 En DíAZ GIMÉNEZ, O. (1878-81), obra citada en nota 16, núm. 34 y 50, quedan recogidas las principales ideas de dicho autor respecto al evolucionismo geológico.

19 GLICK, T. (1982), Darwin en España, Barcelona, Península.

20 DíAZ GimÉNEZ, O. (1878-81), obra citada en nota 16, núm. 35. 
Unos párrafos después, tras una interesante reseña biográfica de Darwin, en la que Díaz no oculta su admiración por el inglés, entra de lleno en el estudio científico de su obra. Primero, aborda la justificación de las teorías darwinistas a través de la fertilidad y fecundidad de las especies; ofrece varios ejemplos al respecto, mostrando notables conocimientos de fisiología y etología animal. Se adentra luego en el tema de la lucha por la vida, el cual engloba dentro de otras antagonías físicas (acciónreacción; dualidad de la carga) y químicas (ácido-base). Y trata finalmente sobre la selección natural en cuya defensa trae a colación el ancestral uso empírico de la artificial para la cría de animales.

Posteriormente, pasará a estudiar la (para él evidente) ascendencia común del hombre y el mono, aunque en este terreno separará previamente a los cecopitecos de los antropoides, ajustando su análisis comparativo sólo a estos últimos ${ }^{21}$. Pero junto a estos contenidos de corte zoológico, realizará también Olayo Díaz una amplia incursión en el polémico tema del darwinismo social. Respecto al mismo, establece primero la necesidad de no obviar la naturaleza animal del hombre a la hora de estudiar el fenómeno social. Asume sin reparos la presencia de diferencias (a veces muy hondas) entre los seres humanos. Pero a su vez, ve ineludible intervenir sobre el propio proceso natural a fin de conseguir un orden social no ajeno a valores de tipo moral:

«... no es posible, moralmente hablando, sacrificar a los débiles, la sociedad tiene más bien la obligación de compadecerlos, de aliviar en lo posible las anomalías de la suerte, las privaciones y sufrimientos de la vida (...). Esta es la característica de nuestra especie, y no la morfología símica, como pretenden algunos» ${ }^{22}$.

Por su parte, a la hora de abordar la cuestión del dominio de unos pueblos sobre otros, Olayo Díaz no llegará nunca a justificarla, pero sus argumentos serán ahora menos concluyentes. Al fin y al cabo ya dijimos que fue un típico portador de las contradicciones de su tiempo, y éste fue el del colonialismo. Así, pese a haber calificado previamente de «despojo efectuado por la astucia o por la fuerza» la colonización hispana y portuguesa de América, admite después que, mal que nos pese:

«Hay un fallo superior que absuelve a la humanidad de estas invasiones, a nombre de la concurrencia vital, de la lucha por la existencia (...). La cuestión de derecho, tratándose de las riquezas que encierra nuestro planeta se halla también subordinada al mayor bien y provecho de la humanidad; y los títulos de propiedad corresponden al que pueda hacer más útil y legítimo uso de la cosa poseída» ${ }^{23}$.

21 Puede verse esta cuestión en DíAZ GIMÉNEZ, O. (1878-81), obra citada en nota 16, núm. 107.

22 DíAZ GimÉNEZ, O. (1878-81), obra citada en nota 16, núm. 75

23 DíAZ GIMÉNEZ, O. (1878-81), obra citada en nota 16, núm. 85 


\section{LA LABOR COMO ENCARGADO DE LA ESTACIÓN METEOROLÓGICA}

A instancias del Ministerio de Fomento, la Estación Meteorológica de Murcia fue creada por R.D. de 5/3/1860 con sede en el Instituto de Segunda Enseñanza, aunque su material e instrucciones de uso no fueron remitidos a éste sino a lo largo del bienio siguiente, justo coincidiendo con la incorporación de Olayo Díaz. En realidad, la creación de dicha Estación se produjo en un marco general, pues el mismo decreto que la propicia preveía la creación de otras 22 en distintas capitales de provincia, nombrándose como encargados de las mismas, allá donde los hubiese, a los catedráticos titulares de Física.

Las instrucciones de uso remitidas, eran bastante precisas ${ }^{24}$, pero por contra, el material suministrado al Instituto para ejecutarlas era más bien escaso y deficiente ${ }^{25}$ : un barómetro de Winckelmann (tipo Fortin), dos termómetros de máxima-mínima (modelo Casella, modificado por Philiph), dos termómetros de Fastre formando sistema para medir humedades relativas (poco operativo ante el excesivo tamaño e inadecuado soporte de los mismos), un pluviómetro y un vaso evaporatorio.

Tales circunstancias, motivaron a Olayo Díaz a dirigirse repetidas veces a la Administración en demanda de nuevos y mejores instrumentos, pero su escaso éxito en el empeño le movió a iniciar un programa de adquisiciones con los fondos propios del Instituto. Así, entre otros materiales menores, trajo dos nuevos psicrómetros (con los que sustituir ventajosamente al sistema de termómetros Fastre), un atmóscopo de zinc, un higrómetro de Daniell, un udómetro de Babinet y un anemómetro de Robinson.

Ya bien pertrechado, Díaz realizó minuciosamente durante años todas las observaciones que le eran demandadas desde el Ministerio. Pero lo importante es que no se limitó a remitir de oficio tales registros, sino que aprovechó para proyectarlos, de forma original y eficaz, hacia el conjunto de la sociedad murciana a través de la prensa. Esmeradas colecciones de dichos registros fueron publicados en revistas como Aura de Murcia (1871) y El Semanario Murciano (1878-81). Normalmente lo hizo con periodicidad decenal o mensual, aunque facilitó también en varias ocasiones interesantes resúmenes con los valores medios por períodos trianuales o quinquenales ${ }^{26}$.

Pero debe añadirse que en tales cuadros y resúmenes, los datos meteorológicos nunca fueron plasmados sin más. Díaz los acompañó de una sección denominada «Accidentes» desde donde realizó una notable divulgación de los fundamentos de la

24 HeRnÁNDEZ PinA, F. (1983), El primer centro oficial de Segunda enseñanza en Murcia, Murcia, Universidad de Murcia, pp. 116-122.

25 LÓPEZ FERNÁNDEZ, C., VALERA, M. (1997), «La labor científica del catedrático Olayo Díaz Giménez en el Instituto Provincial de Segunda Enseñanza de Murcia», Actas del VI congreso de la SEHCYT, Segovia (en prensa).

26 Ver, respectivamente, Aura Murciana (1871), núm. 3, 4, 6, 8, 13, 18, 19, 20, 21, 22, 23 y 24 . y El Semanario Murciano (1881), núm. 158, 161, 165, 170, 175, 179, 182, 185, 189, 195, 198 y 199. 
Meteorología, a la vez que ofreció abundantes comentarios sobre la climatología murciana. En este terreno, incidió especialmente en la influencia de ésta en cuestiones vitales para la economía de la tierra, como la agricultura y sericultura. También se cuidó de criticar científicamente determinas costumbres laborales de los huertanos.

Es interesante señalar que en una de sus colaboraciones en el Semanario Murciano, quedó reproducida la carta-informe que envió al Director del Observatorio Astronómico de Madrid analizando las causas y efectos de la riada de Santa Teresa ${ }^{27}$. Dicho evento, acaecido en Octubre de 1879, fue de los más devastadores que ha conocido Murcia: hubo un total de 782 víctimas, y propició un movimiento internacional de apoyo en el que participaron activamente varios intelectuales y escritores extranjeros, como Emile Zola.

Pero aún hay más que decir sobre la labor meteorológica de Olayo Díaz, y es que a poco de instalarse la Estación, en 1865, el propio Instituto le editó un libro relativo a su labor en aquélla. El título de dicha obra, Año meteórico de Murcia. 1864, es algo engañoso, pues su contenido no es una mera recopilación de los registros obtenidos en la Estación durante dicho año. En realidad, el planteamiento de la obra es tan genérico, que ésta nos permite considerar a su autor como el verdadero introductor de la Meteorología en Murcia. Merece la pena realizar algunos comentarios sobre el libro, el cual, muy bien valorado por la Academia de Ciencias, le valió a Díaz el nombramiento de miembro corresponsal de la misma en 1867.

Dividido en dos grandes partes, la primera de ellas tiene un enfoque general y un nivel teórico considerable. A lo largo de las 8 secciones iniciales de la misma, y con el pretexto de describir el instrumental de la Estación, realiza Olayo un estudio físico detallado de los principales fenómenos meteóricos: presión atmosférica, humedad, temperatura, evaporación, lluvia, aire, luz y electricidad meteórica. Es este último fenómeno el que se ve con más atención, incluyéndose dentro del estudio del mismo una breve historia de la electricidad como ciencia y un buen análisis de los fenómenos de electrificación por influencia.

De todos los fenómenos citados, se revisan con detalle tanto las causas que los producen como sus consecuencias y métodos de medida. Hay luego otra sección dedicada a estudiar (de forma bastante exhaustiva por cierto) los diferentes tipos de nubes tormentosas. Y por último aparecen otras 5 secciones, ya menos teóricas, y cuya inclusión parece obedecer más a motivos editoriales que científicos; están centradas en un fenómeno muy particular: el rayo, del que se estudian sus causas, naturaleza, efectos destructivos y métodos de prevención.

Pese al enfoque genérico que, según vemos, presidió siempre esta primera parte del Año meteórico, aborda Olayo Díaz en ella algunas cuestiones referentes específi-

27 DíAZ GimÉnEZ, O. (1879), «De la Estación Meteorológica de Murcia al Ilmo Sr. D. Antonio Aguilar, Director del Observatorio Astronómico de Madrid», El Semanario Murciano, 90. 
camente a Murcia. Destacaríamos la determinación experimental de la profundidad de la capa termostática de la ciudad, o capa interior de temperatura constante donde acaba la influencia solar ${ }^{28}$. Díaz compara sus datos, obtenidos a partir de un pozo de $7 \mathrm{~m}$. excavado en el patio del Instituto, con los aportados por Cassini en el Observatorio de París (1771). En el caso murciano la citada capa se sitúa a los 4m., con una temperatura estable de $16.7^{\circ}$ (uno por encima de la temperatura media de la ciudad, al revés de lo apreciado en el caso parisino). Otros autores a los que recurre a lo largo de la obra para cotejar datos son Saussure, Humboltd y Kaemtz.

La segunda parte es más descriptiva, y está dedicada específicamente a la meteorología de la Región Murciana. Dividida en 4 amplias secciones, correspondientes a las 4 estaciones climatológicas del año, se plasman en cada una de ellas los valores mensuales medios de los registros obtenidos desde la Estación. Estos hacen referencia, en todos los casos, a presión atmosférica, temperatura, humedad relativa, evaporación, lluvia, celaje y vientos. Ya de forma más ocasional, son recogidas algunas incidencias y cifras relativas a otros fenómenos atmosféricos particulares, como las tempestades, la electricidad meteórica y la niebla. Se incluye al final de la obra, una pormenorizada colección de los datos meteorológicos murcianos del trienio 1863-65.

Pero conviene señalar que, al igual que ocurrió con sus colaboraciones en la prensa, aquí Olayo Díaz tampoco se limita a publicar unas frías relaciones de datos numéricos, sino que estos van siempre acompañados de amplios comentarios. La mayoría están referidos a la incidencia general de la climatología murciana sobre las actividades agrícolas propias de la tierra, pero toca además con especial interés (cosa que también había hecho desde la prensa) el tema de la cría del gusano de seda ${ }^{29}$.

En este terreno, insiste sobre tres cuestiones (por desgracia muy poco consideradas tradicionalmente por los huertanos): la conveniencia de no alimentar al gusano con moreras húmedas, el evitar su hacinamiento y el cuidar en extremo la deshumidificación de los zarzos; advierte Díaz que en caso contrario se favorece mucho la propagación de la epizootia denominada «pinto» o «fuligo», debida, según el mismo comenta, al hongo parasitario botrytis bassyana. Aquí, Olayo es consciente de que sus escritos difícilmente van a llegar al modesto huertano; ello le impele a exigir a los propietarios que se responsabilicen de fomentar ese cambio de hábitos:

«Aun cuando la reforma de males inveterados fuera posible, no estaría al alcance de los pobres; más debieran intentarla los hombres acomodados ó el espíritu de asociación, sacando la industria sericícola de la esclavitud en que la tiene la pobreza, para colocarla a la altura de esas grandes esplotaciones de que ofrecen ejemplo los dandoleres de Italia» (en referencia a las instalaciones promovidas por el conde Dandolo) ${ }^{30}$.

\footnotetext{
28 DíAZ GimÉnez, O. (1865), Año meteórico de Murcia. 1864, Murcia, Instituto Provincial, pp. 29-31.

29 DíAZ GiMÉNEZ, O. (1865), Año meteórico de Murcia. 1864, Murcia, Instituto Provincial, pp. 167168 y $177-179$.

30 DíAz GimÉneZ, O. (1865), Año meteórico de Murcia. 1864, Murcia, Instituto Provincial, p. 169.
} 
Y en otro orden de cosas, yéndonos ya a la parte final del libro, vemos que allí aborda Olayo Díaz una cuestión bastante más original que las anteriores, como es la posible incidencia de la concentración del ozono atmósferico en la propagación de las epidemias de cólera. Le motiva a ello el que Murcia acababa de padecer una de ellas (Noviembre 1864-Febrero 1865), aunque Díaz ya había vivido ese mismo trance en dos ocasiones anteriores. Sobre el tema, había una determinada corriente de opinión médica desde la que se defendía que la mayor presencia de ozono en la atmósfera, por las bien conocidas condiciones antisépticas de éste, debía ser un factor amortiguador de la acción colérica.

Sin embargo, tras mostrar los resultados de las mediciones practicadas desde la Estación durante los últimos 4 meses de la epidemia ${ }^{31}$, Díaz hace ver que, contrariamente, justo vienen a coincidir las alzas de ozono con los días de mayor virulencia de la enfermedad. Así, ésta tuvo su apogeo durante los dos meses finales de 1864, decayendo ya a lo largo de Enero y Febrero de 1865; en cambio, los máximos de ozono durante esos 4 meses, referidos siempre a fases de 10 días, fueron: Noviembre (1918-10), Diciembre (9-12-8), Enero (12-12-13) y Febrero (7-9-9). Ante ello, interpreta que la indudable acción antiséptica del ozono, se ve contrarrestada por las peculiares condiciones meteorológicas que favorecen el alza de éste: humedad, nubosidad, bruma y ausencia de vientos secos.

\section{SEMBLANZA FINAL Y CONCLUSIONES}

Tras la visión general que hemos ofrecido de la peripecia vital, científica y docente de Olayo Díaz, se desprenden varias conclusiones que nos dibujan un perfil bien definido para el mismo; serían las siguientes:

- Con independencia de su ya significada labor antes de llegar a Murcia, es claro que Díaz desarrolla en esta ciudad la parte más notable de su labor científica y docente. A estos efectos, y con toda propiedad, se le puede considerar un científico murciano; por más que en Murcia (como suele ocurrir en estos casos) sea un perfecto desconocido.

- Olayo Díaz no llevó a cabo una labor científica propia significativa, aunque sus modestas aportaciones (determinación de la profundidad de la capa termostática, estudio de las relaciones ozono-cólera o estudios sobre la cría del gusano de seda) estuvieron planificadas con el máximo rigor que le permitían sus escasos medios.

31 DíAz GiméNEZ, O. (1865), Año meteórico de Murcia. 1864, Murcia, Instituto Provincial, pp. 229-230. 
- Sí es, por contra, perfectamente destacable su notable tarea como forjador de una cultura científica en tierras murcianas. Su protagonismo a la hora de erigir instituciones culturales preocupadas por la ciencia (Liceo), sus numerosas colaboraciones en la prensa sobre temas científicos diversos, su decisivo papel como introductor del evolucionismo en la región, la publicación de su libro sobre Meteorología y las completísimas observaciones de esta naturaleza realizadas desde la Estación, son sólidos avales en este terreno.

- Por otra parte, puede ser también considerado Díaz uno de los máximos responsables de la creación de una infraestructura material e institucional de tipo científico en la Murcia decimonónica: el Gabinete de Física, la Estación Meteorológica y la Universidad Libre, son buenas pruebas. Todo ello facilitó, aunque en diferentes grados y maneras, la formación media de importantes figuras científicas: algunas foráneas (Ventura de los Reyes Prósper) y otras autóctonas (José Hernández Ardieta), sin olvidar a destacados cuadros políticos (Juan de la Cierva y Antonio García Alix).

Es cierto que Olayo Díaz no estuvo sólo en esta tarea; otros científicos murcianos (o ejercientes en Murcia) como Angel Guirao Navarro, Francisco Cánovas Cobeño y Andrés Martínez Cañada (Historia Natural), Tomás Museros Rovira (Agricultura) y Bernardino Sánchez Vidal (Matemáticas), fueron compañeros suyos de viaje. Sólidos profesionales, conformaron ese núcleo de intelectuales (también perfectos desconocidos en Murcia) que hicieron que esta ciudad no quedara totalmente aislada del trepidante progreso científico decimonónico.

Pero sin duda, Olayo Díaz destacó con luz propia entre ellos. Fue así un claro ejemplo de ese «científico intermedio» que, aunque no realizase aportaciones originales importantes, preparó adecuadamente el terreno para otros. Uno de los muchos que permitieron mantener viva la llama de la ciencia en nuestro país durante la centuria pasada.

Fue, además, un hombre preocupado por su entorno: progresista en lo ideológico y sensible ante lo social, aunque más bien retraído a la hora de la acción política. Portador de una gran fé en el progreso científico como redentor de los males humanos, pero con planteamientos excesivamente idealistas a la hora de reclamar los cambios sociales necesarios para ello. Algunas contradicciones, en suma, para un personaje que, como decíamos al principio, no fue sino un típico hijo de su tiempo. 